\title{
SOME CHARACTERISTICS OF NEUROMUSCULAR BLOCK IN THE RESPIRATORY MUSCULATURE IN ANAESTHETIZED MAN
}

\author{
Chingmuh Lee
}

ONE MAJOR FUNCTION of the neuromuscular block is relaxation of the respiratory musculature, including the abdominal muscles, the diaphragm, and the intercostals. Post-operatively, restoration of muscle power in the respiratory musculature is of more immediate concern than the thumb twitch. However, because the respiratory muscles are not as readily accessible, the thumb twitch is commonly employed clinically for monitoring and for investigations.

Unfortunately, block of the thumb twitch does not necessarily equal block of the respiratory force. ${ }^{I}$ Basically, the thumb twitch is an artificial contraction elicited by electric shocks. Respiratory movement, by contrast, results from tetanic volleys of nerve impulses of variable frequency which constitute the respiratory drive.

This study was undertaken to elucidate some characteristics of neuromuscular block in the respiratory musculature in man, using a simplified approach by simulating mild expiratory obstruction.

\section{Methods}

Sixty-four adult patients were studied under surgical anaesthesia. All patients were free from neuromuscular or cardiopulmonary disease, relatively healthy (ASA Class I or II) and had no abnormalities in blood chemistry. Patients with abdominal distention, obesity, or in restricting surgical positions were excluded.

Premedication consisted of a barbiturate (quinalbarbitone or pentobarbitone $100 \mathrm{mg}$ ) and atropine 0.4 to $0.6 \mathrm{mg}$ intramuscularly one-half to two hours before induction. Anaesthesia was induced with thiopentone (100 to $450 \mathrm{mg}$ intravenously in divided doses) and maintained with halothane ( 0.3 to 1.0 per cent) and nitrous oxide ( 60 per cent) in oxygen. Tracheal intubation was facilitated by topical anaesthesia of oropharynx, larynx and trachea with 3 to $5 \mathrm{ml}$ of 4 per cent lidocaine. The study was started not less than 30 minutes after induction and only when both the anaesthetic requirement and the surgical procedure had been relatively stable. All patients were breathing spontaneously. The end-expiratory carbon dioxide concentration was monitored by capnograph in most instances.

The pop-off valve on the anaesthesia breathing circuit was tightened slightly to impose an expiratory resistance. The valve was adjusted to open at the set plateau airway pressure of $5 \mathrm{~cm} \mathrm{H}_{2} \mathrm{O}$. With five litres of fresh gas input per minute the lowest inspiratory airway pressure was usually just above zero, approximately 1 to $2 \mathrm{~cm} \mathrm{H}_{2} \mathrm{O}$ in a steady state. The obstruction, while well-tolerated by all

Department of Anaesthesiology, UCLA School of Medicine, Harbour General Hospital Campus, Torrance, California 90509, U.S.A. 

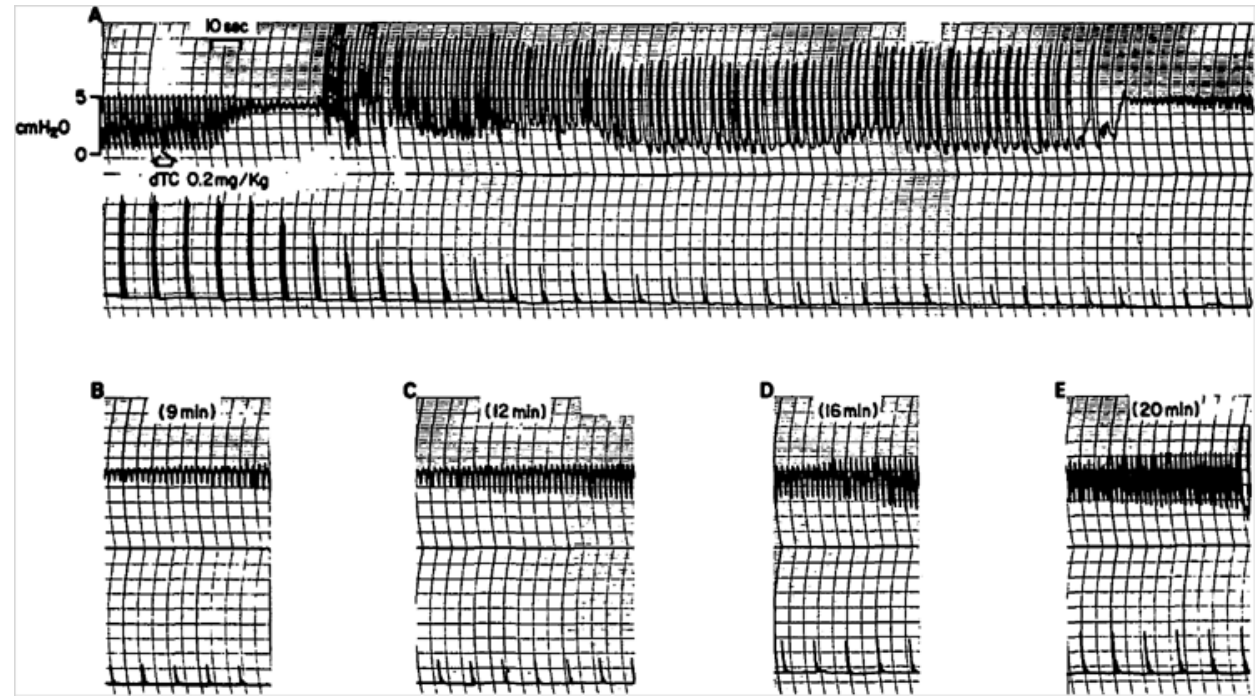

Figure 1. Neuromuscular blocking effects of d-tubocurarine $(0.2 \mathrm{mg} / \mathrm{kg}$, at arrow) in the respiratory musculature (upper tracing) and in the thumb (lower tracing) in an anaesthetized patient with the trachea intubated, recorded simultaneously for comparison. An expiratory resistance was imposed by a slightly tightened pop-off valve which was set to permit escape of anaesthetic gases from the breathing circuit at a set plateau airway pressure of $5 \mathrm{~cm}_{2} \mathrm{O}$, during expiration. Inspiration lowered the airway pressure to $1 \mathrm{~cm} \mathrm{H_{2 }} \mathrm{O}$. Loss of ability to exhale against resistance, as indicated by narrowing of the airway pressure excursion following drug injection, quantitated the respiratory paralysis. Tall artifacts which followed were the result of artificial ventilation. Four thumb twitches, 0.5 second apart (train-of-four), were elicited intermittently. Points of interest demonstrated are: rapid onset and profound block of the respiratory musculature $(A)$, early recovery of respiratory power $(B, C, D)$ and slow onset and slow recovery of the thumb twitches. The respiratory movement was still asynchronous after 20 minutes. Time from injection: $\mathrm{B}, 9 \mathrm{~min} ; \mathrm{C}, 12 \mathrm{~min} ; \mathrm{D}, 16 \mathrm{~min}$; and E, $20 \mathrm{~min}$.

patients, did create a slight but definite increase in the respiratory effort. The airway pressure excursion was recorded on an oscillograph (Grass Model 7 Polygraph) via a transducer (Statham blood pressure transducer, filled with air) interposed between the tracheal tube and the breathing circuit. Relaxants were not given until the recorded airway pressure had assumed regular rhythmic excursion again.

A calculated dose of a muscle relaxant was injected as a bolus intravenously. In 40 instances the relaxant was d-tubocurarine in doses of 0.03 to $0.35 \mathrm{mg} / \mathrm{kg}$ body weight, while in 24 other cases it was succinylcholine 0.02 to $0.33 \mathrm{mg} / \mathrm{kg}$. Narrowing of the recorded airway pressure excursion was used as an indicator of the respiratory block. A non-fluctuating straight line indicated apnoea. Assisted respiration or controlled ventilation was instituted as indicated to avoid hypoventilation. The observation time was limited to one to five minutes from injection to avoid interferences from altered respiratory drive. Usually this provided sufficient time for adequate observations to be made. Each patient received only one dose of one relaxant drug during the study.

In 20 of these 64 patients (ten receiving d-tubocurarine, ten receiving succinylcholine) the thumb twitch was studied simultaneously, according to the procedure 
described recently using the train-of-four stimulation. ${ }^{2}$ Briefly, the ulnar nerve was stimulated intermittently at the wrist with four stimuli 0.5 second apart. The thumb twitch was quantitated by measuring the twitch height recorded on the oscillograph. The percent block of the first and the fourth twitch were calculated separately.

\section{RESULTS}

All patients responded immediately to the imposed resistance by a slightly increased respiratory effort, characterized by a synchronized thoraco-abdominal expiratory strain. A steady state was established promptly, usually within 1 to 6 minutes. This was well tolerated for the duration of the study.

\section{d-Tubocurarine}

Following the intravenous bolus injection of d-tubocurarine the onset of respiratory block was observed within 30 seconds, reaching a peak within another 30 seconds, long before onset of the block of the thumb twitch (Figure 1). Clinically, the respiratory movement became asynchronous and obviously weakened. The tidal volume decreased. The degree of this block in relation to the dose of relaxant is shown in Figure 2. The 50 per cent block dose was approximately $0.11 \mathrm{mg} / \mathrm{kg}$ body weight as calculated from Figure 2 .

The time course of the respiratory block that followed also differed from the time course of the thumb block (Figure 1). In general, respiratory neuromuscular recovery took place in two phases (Figure 3). Characteristically, the first phase of recovery started immediately after the peak effect and lasted only one minute. Following injection of a small dose of d-tubocurarine, complete recovery occurred in this phase, so that the total duration of block was very short and disproportionately short when compared with the time course of neuromuscular block of the thumb twitch by d-tubocurarine. The second phase of neuromuscular block in the respiratory musculature was long-lasting but the recovery was always slightly ahead of that of the thumb twitch (Figure 1). The exact duration of the second phase of recovery could not be determined because of the necessity for ventilatory support. Besides, the respiratory drive could have been changed by hypoventilation or by controlled ventilation.

Figure 3A illustrates light respiratory block. The patient recovered completely from an approximately 30 per cent block within one to two minutes. A second phase of block was not detectable.

Figure 3B illustrates a typical biphasic recovery. The respiratory musculature recovered from an approximately 75 per cent block within one minute. The remaining 50 per cent took over 45 minutes to recover. Figure $3 \mathrm{C}$ illustrates profound respiratory block. The profound residual block obscured the initial recovery.

Unless the block was prolonged, the respiratory rate did not change. The thoracoabdominal respiratory effort did not diminish. Therefore, the respiratory block observed, with its characteristic rapid onset and fast initial recovery, appeared to be neuromuscular in nature, rather than being the result of central depression of the respiratory drive.

An augmented respiratory drive did appear to accelerate recovery or compensate 


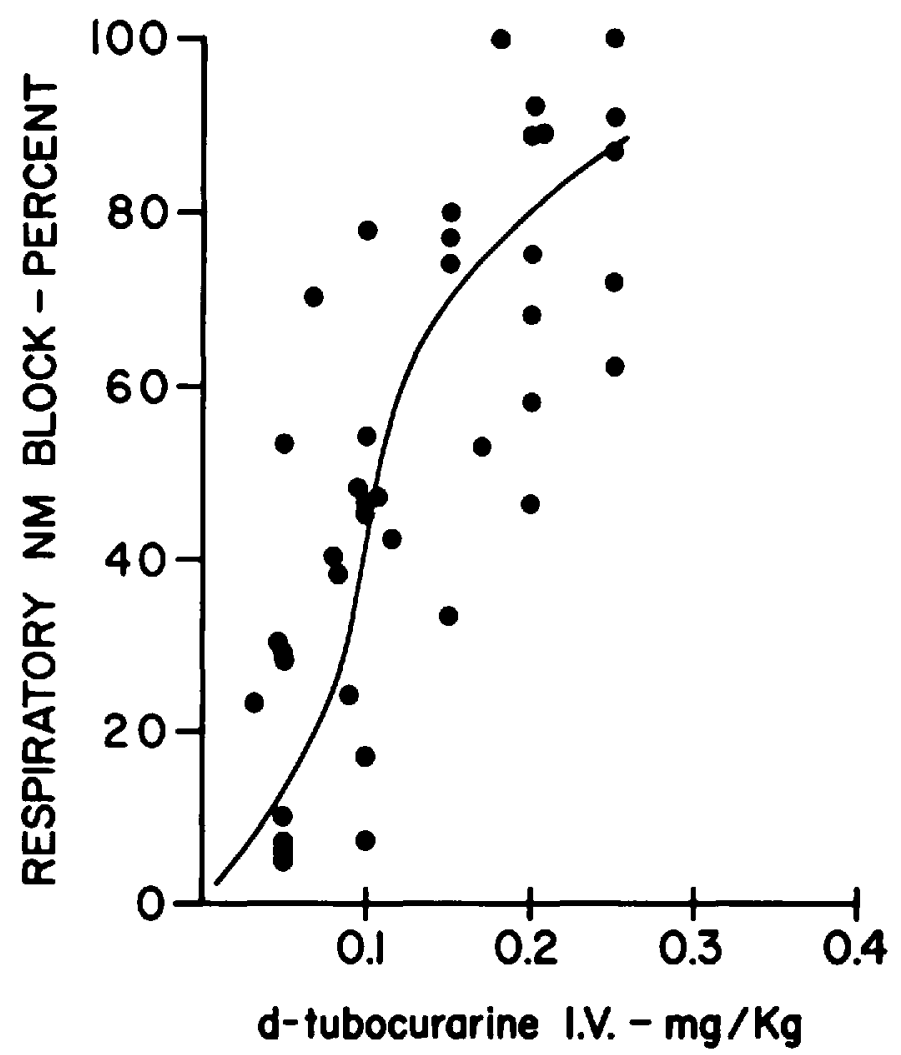

Figure 2. Degree of d-tubocurarine blockade of the respiratory musculature in 40 anaesthetized relatively healthy patients breathing spontaneously against a resistance with the trachea intubated. The ED50 was approximately $0.11 \mathrm{mg} / \mathrm{kg}$.

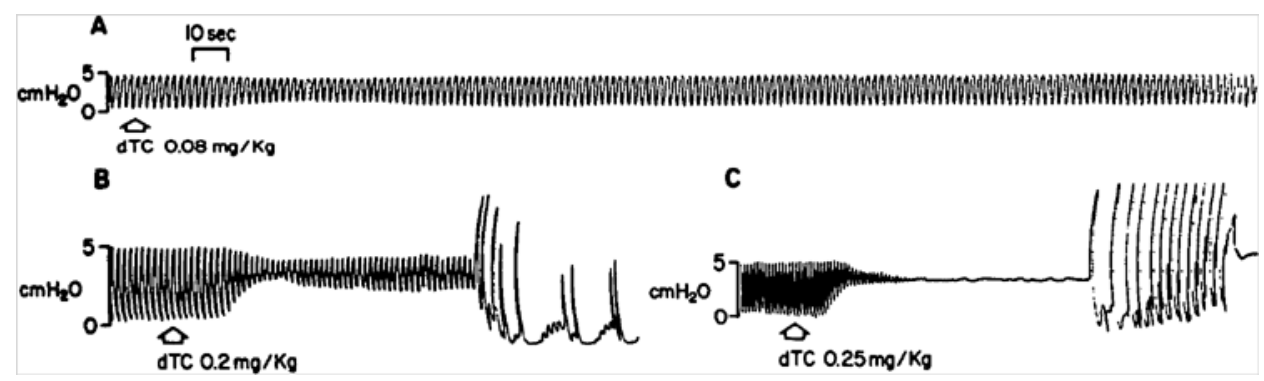

Figure 3. Typical time courses of respiratory neuromuscular block by d-tubocurarine illustrated by three patients.
A. A 30 per cent block from $0.08 \mathrm{mg} / \mathrm{kg}$ ( $6 \mathrm{mg}$ in a $70 \mathrm{~kg} 6$-ft man), lasted only 1 to 2 minutes. Note the disproportionately short duration of block.
B. Biphasic response observed from $0.2 \mathrm{mg} / \mathrm{kg}$. An initial partial recovery of less than one-
minute duration followed by a prolonged persistent block.
C. Deep persistent block from $0.25 \mathrm{mg} / \mathrm{kg}$ obscured the initial recovery. 


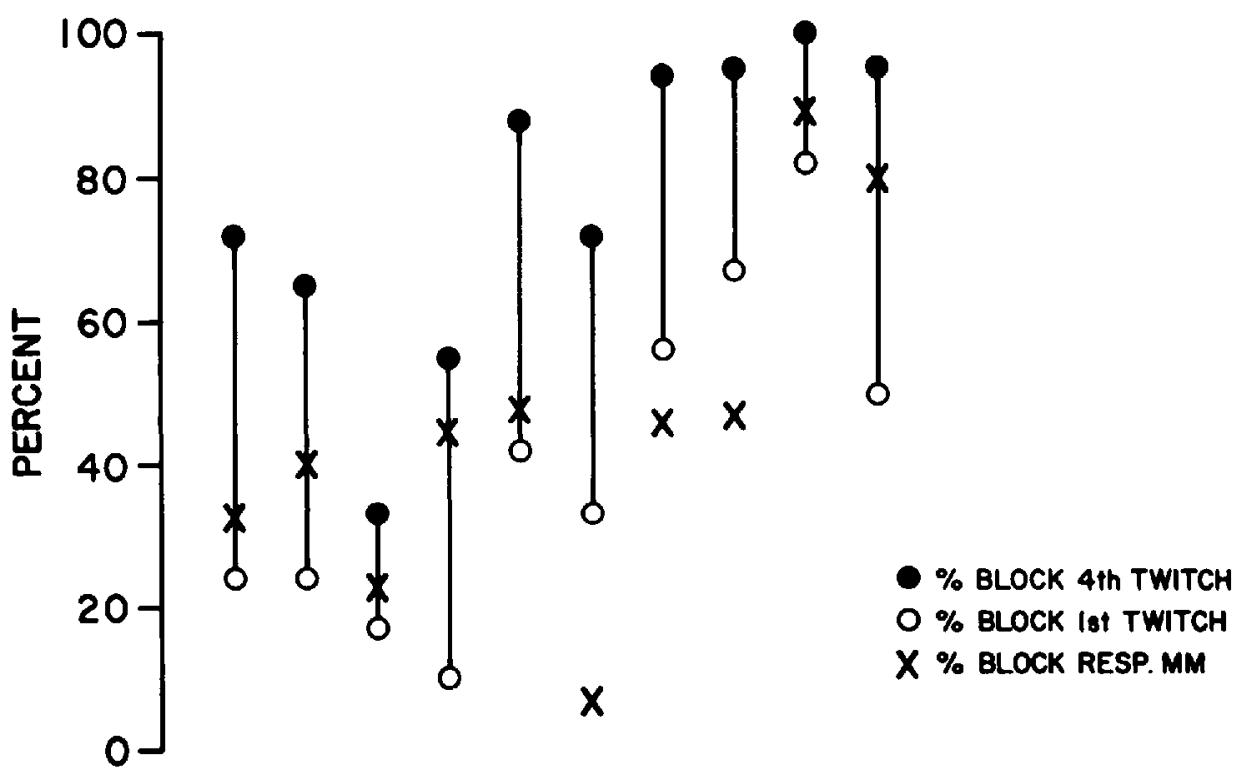

Figure 4. Sensitivities to d-tubocurarine block: respiratory power and the thumb twitches compared. Thumb twitches, which were elicited intermittently by stimulating the ulnar nerve four times, 0.5 second apart, were blocked differently, the fourth being most sensitive. Each set of circle, dot and cross represents one patient. Each patient received a different amount of d-tubocurarine. Peak effects of three parameters were compared. The respiratory musculature was more sensitive than the first twitch in seven out of ten patients. The fourth twitch was the most sensitive in every case.

for the respiratory block, because tracheal stimulation or surgical incision deliberately applied during the observation markedly reversed the respiratory block but not the thumb twitch. This could be observed better under light anaesthesia and in the presence of tachypnoea.

Figure 4 compares the sensitivity of the respiratory block with that of the first and the fourth twitches of the train-of-four in 10 subjects treated with d-tubocurarine. With three exceptions, the first twitch, a single shock of $0.1 \mathrm{~Hz}$, by a slight margin did not reach the respiratory block when peak effects were compared. The fourth twitch markedly exceeded the block in every case.

\section{Succinylcholine}

In contrast to d-tubocurarine, succinylcholine blocked the respiratory musculature and the thumb twitch similarly, with rapid onset and fast recovery (Figure 5). No biphasic time course was observed.

The respiratory excursion was slightly more sensitive than the thumb twitch; that is 50 per cent respiratory block corresponded to 40 per cent thumb twitch block. The time course was slightly ahead of the thumb twitch by approximately one minute. The 50 per cent block dose was approximately $0.08 \mathrm{mg} / \mathrm{kg}$ (Figure 6). 

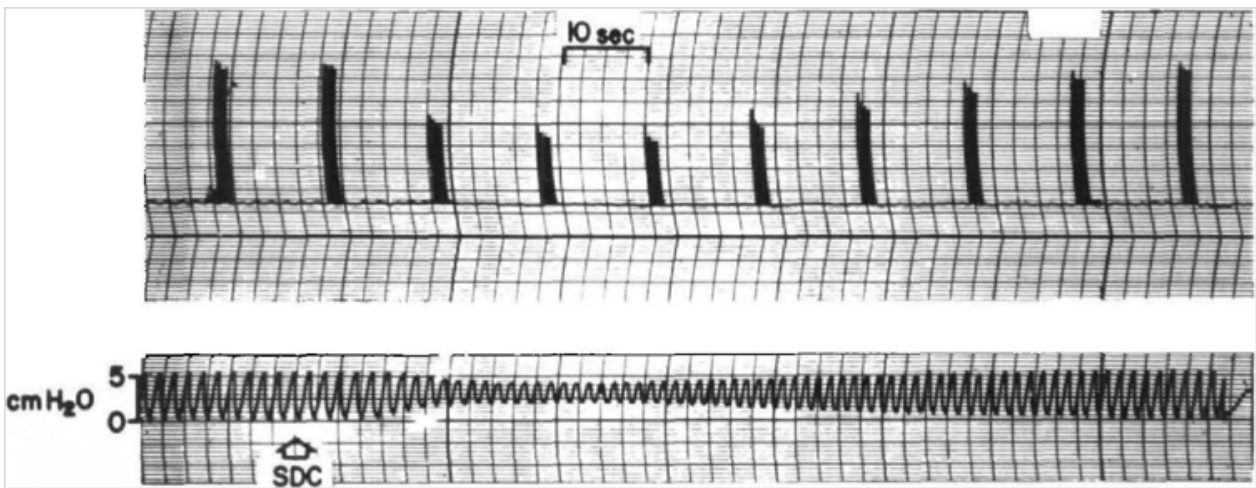

Figure 5. Neuromuscular blocking effects of succinylcholine in the respiratory musculature and in the train-of-four thumb twitches. A bolus of $0.28 \mathrm{mg} / \mathrm{kg}$ blocked the respiratory musculature, the first twitch and the fourth twitch by 57 per cent, 42 per cent and 55 per cent respectively. The time courses were also similar with respiratory block leading slightly.

\section{Discussion}

The diaphragm and respiratory muscles have been compared to other muscles, including the thumb muscles, by comparing elicited diaphragmatic contraction, tidal volume or vital capacity to grip strength, elicited thumb twitch, or other performances of the limb muscles. ${ }^{1,2-6}$

Generalization of the comparative sensitivity camot be made without specifying the conditions under which observations are made. The present study imposed to the respiratory musculature a measured amount of small stress, which also slightly enhanced the respiratory drive, and estimated the patient's ability to cope with a simulated mild airway obstruction of common occurrence. This was compared to a common method of monitoring the neuromuscular block, namely the thumb twitch. A comparable degree of airway obstruction occurs when the breathing bag is distended, when PEEP is applied and when the airway is narrowed by a tracheal tube, mucus deposition or oedema of the mucosa.

The results demonstrate that the respiratory musculature as a whole is bighly sensitive to neuromuscular block. Even with a secure airway, a healthy anaesthetized man in the supine position cannot breathe against a mild airway obstruction after receiving a relatively small dose of relaxant.

Although a resting man under anaesthesia needs only a small fraction of his respiratory muscle power to maintain an adequate minute volume, and an increased respiratory drive can overcome some neuromuscular block, or compensate for decrease in tidal volume by increasing the rate, such considerations, however, do not substantiate significant respiratory sparing, but rather represent compensated distress at the expense of respiratory functional reserves.

The recovery in the respiratory musculature preceded that in the thumb. Except in the case of a very small d-tubocurarine block as illustrated in Figure 3A, however, the difference represents a relatively small fraction of the total duration of 


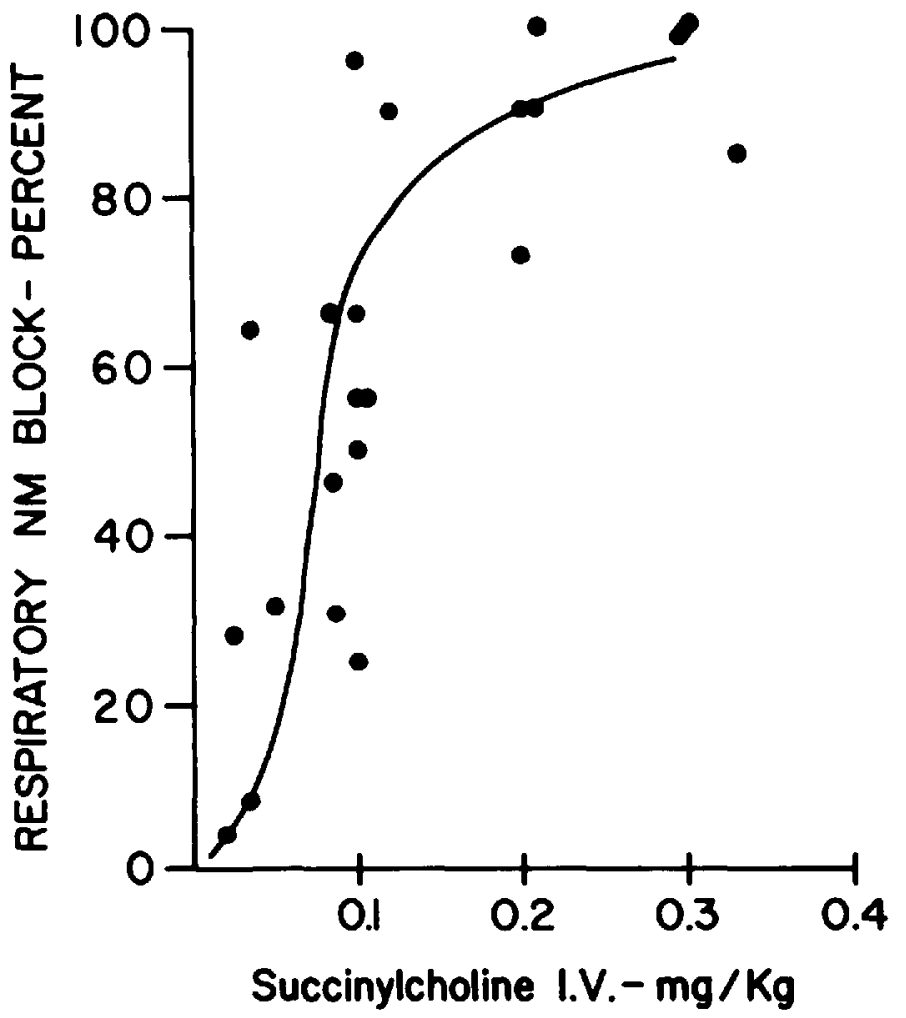

FIGURE 6. Sensitivity of the respiratory musculature to succinylcholine block, in 24 relatively healthy anaesthetized patients with tracheal intubation breathing spontaneously against a resistance. The ED50 was approximately $0.08 \mathrm{mg} / \mathrm{kg}$.

the block. In general, the duration of the d-tubocurarine block in both muscle groups is long. Recently Rigg, Engel and Ritchie have demonstrated that in awake volunteers receiving small doses of $d$-tubocurarine, the vital capacity is less depressed than the grip strength. ${ }^{6}$ This probably can be explained by the present observation that the respiratory muscles recover earlier, so that when compared simultaneously they appear "spared." In addition, the peak respiratory block might have been missed because in their studies the relaxant was injected slowly.

Interestingly, a d-tubocurarine block of the respiratory musculature is more sensitive than the first twitch, but less sensitive than the fourth twitch of the train-of-four. Conceivably, this suggests that when a patient is properly anaesthetized and his tissues are handled gently, the thoracoabdominal musculature can be relaxed satisfactorily by administration of just enough d-tubocurarine so that when four shocks 0.5 second apart are applied to the ulnar nerve, there is a markedly diminished response to the first stimulus; but because the train of twitches decreases steadily, it becomes totally blocked by the fourth twitch. This corresponds to an $80-95$ per cent block of the thumb twitch, as measured by the conventional single shock method. ${ }^{7}$

The present report substantiates a previous recommendation that a thumb 
block of 75-90 per cent is adequate for satisfactory abdominal relaxation in properly anaesthetized man. ${ }^{1,8}$ It also explains why inadequate anaesthesia makes abdominal relaxation unsatisfactory despite profound thumb block by demonstrating that arousal and increased respiratory drive resulting from surgical stimulation in lightly anaesthetized patients or cough resulting from secretions in the trachea selectively reverse the neuromuscular block in the thoracoabdominal muscles, but not the block in the thumb. Apparently, proper ventilation, gentle handling of the tissues and a clean patent airway also play important roles in relaxation of the abdominal muscles. Clinically, because complete block of the thumb twitch is usually neither necessary nor advisable ${ }^{1,8-10}$ and because a control twitch is seldom available for calculation of the per cent block, it is suggested that train-of-four be employed more frequently.

The characteristic rapid onset, profound block and rapid partial recovery of neuromuscular block in the respiratory musculature after d-tubocurarine had not been recognized before. Multiple factors probably account for the differences between the respiratory musculature and the thumb. These include differences of histology, blood supply, and local temperature. ${ }^{3-5,11}$ However, the unique time course of the respiratory neuromuscular block can best be attributed to two factors, tetanic contractions and differences in blood perfusion. It has been shown that block of the thumb twitch lags in time course considerably behind the rapid plasma clearance of d-tubocurarine and that tetanic contractions reverse the residual block. ${ }^{12}$ Conceivably, after the tetanic contractions, the degree of returning residual block will depend on the residual plasma concentration of d-tubocurarine. Therefore, any well perfused muscle with continuous activity will probably recover earlier, more or less paralleling the plasma clearance of d-tubocurarine, rather than lagging behind it. Since the respiratory musculature is well perfused, proximal and tetanizing, the respiratory neuromuscular block will follow the plasma concentration more closely, with rapid onset, profound block and earlier recovery than the thumb twitch. These explanations, however, remain to be substantiated.

\section{SUMMARY}

The ability to breathe against a mild expiratory obstruction was examined in 64 adult patients under halothane-nitrous oxide-oxygen anaesthesia. The trachea of all patients were intubated. It was found that d-tubocurarine $0.11 \mathrm{mg} / \mathrm{kg}$ blocked the respiratory musculature by 50 per cent. The onset of block was immediate, with the peak effect reached within one minute. The duration of block was either very short ( 1 to 2 minutes) or long (paralleling the blockade in the thumb twitch), depending upon the dose of d-tubocurarine. Following injection of a small dose (up to $0.1 \mathrm{mg} / \mathrm{kg}$ ) the respiratory musculature might be blocked by 30 per cent but for only one minute, disproportionately short as compared with the thumb twitch. Following injection of a large dose $(0.1-0.3 \mathrm{mg} / \mathrm{kg})$ the duration was long, but the recovery was only slightly ahead of the thumb. Following an intermediate dose, a biphasic pattern was observed. An initial partial recovery was observed during the first 1 to 2 minutes. Comparison of the respiratory musculature and the thumb twitch revealed that the respiratory musculature was highly sensitive to 
block and has a different time course. Succinylcholine $0.08 \mathrm{mg} / \mathrm{kg}$ blocked the respiratory force by 50 per cent with a time course similar to the block in the thumb twitch. The clinical significance of these observations are discussed.

\section{RÉSUMÉ}

Les caractéristiques du bloc neuro-musculaire de la musculature respiratoire (abdominaux, inter-costaux et diaphragme) ont été étudiées chez 64 patients adultes (de classe ASA I ou II). Tous ces malades ont été anesthésiés avec du protoxyde d'azote additionné d'halothane et ils étaient tous intubés. La valve expiratrice ("pop off") du circuit anesthésique était ajustée de façon à produire une légère obstruction à l'expiration.

Chez 20 de ces patients, on a fait l'étude simultanée de l'excitation intermittente (twicht) du pouce, ceci pour fins de corrélation avec les effets du bloc mateur sur la musculature respiratoire tels que manifestés par la perte pour le malade de la capacité de respirer contre une légère obstruction respiratoire. La durée du blocage musculaire périphérique (mesuré par le "twicht" intermittent du pouce) a été comparée à celle du blocage des muscles respiratoires.

On a trouvé (1) que le bloc des muscles respiratoires survient rapidement, atteignant son maximum en moins d'une minute, (2) que ces muscles sont très sensibles à la tubocurarine, la force respiratoire étant diminuée de 50 pour cent, par une dose de $0.11 \mathrm{mg} / \mathrm{kilo}$, et (3) que la récupération des effets de la tubocurarine se fait en deux étapes, l'une rapide, en une ou deux minutes, et la seconde plus lente, en parallèle à la récupération du "twicht" du pouce.

Avec une petite dose de tubocurarine (jusqu’à $0.1 \mathrm{mg} / \mathrm{kilo}$ ), la récupération est complète dès la première phase, en une à deux minutes, même après une diminution de fonction de l'ordre de 30 à 40 pour cent. Avec des doses plus fortes que $0.1 \mathrm{mg} / \mathrm{kilo}$, la récupération initiale peut passer inaperçue, le phénomène étant masqué par le bloc résiduel. Une dose de $0.08 \mathrm{mg} / \mathrm{kilo}$ de succinylcholine diminue la force respiratoire de 50 pour cent, la durée d'action étant comparable dans les deux groupes de muscles.

Les implications de ces résultats sont discutées.

\section{ACKNOWLEDGMENT}

The author is thankful to Ronald L. Katz, M.D., Professor and Chairman, Department of Anesthesiology, UCLA School of Medicine, for reviewing and criticizing the manuscript during its preparation.

\section{REFERENCES}

1. KATz, R.L. Comparison of electrical and mechanical recording of spontaneous and evoked muscle activity. Anesthesiology 26: 204-211 (1965).

2. LEE, C. Dose relationships of phase II, tachyphylaxis and train-of-four fade in suxamethonium-induced dual neuromuscular block in man. Brit. J. Anaesth. 47: 841 (1975).

3. Paton, W.D.M. \& Zaimis, E.J. The action of d-tubocurarine and of decamethonium on respiratory and other muscles in the cat. J. Physiol. 112: 311-331 (1951). 
4. Taylor, D.B., Prior, R.D., \& Bevan, J.A. The relative sensitivities of diaphragm and other muscles of the guinea pig to neuromuscular blocking agents. J.P.E.T. 143: 187-191 (1963).

5. Alderson, A.M. \& Maclagan, J. The action of decamethonium and tubocurarine on the respiratory and limb muscles of the cat. J. Physiol. (London) 173: 38-56 (1964).

6. Rigc, J.R.A., ENGel, L.A., \& Ritchie, B.C. The ventilatory response to carbon dioxide during partial paralysis with tubocurarine. Brit. J. Anaesth. 42: 105-108 (1970).

7. LEE, C. Train-of-four quantitation of competitive neuromuscular block. Anaesth. and Analg. 54: 649 (1975).

8. KATZ, R.L. \& RYAN, J.F. The neuromuscular effects of suxamethonium in man. Brit. J. Anaesth. 41:381-390 (1969).

9. Churchiml-Davidson, H.C. A philosophy of relaxation, Eleventh annual Baxter-Travenol lecture. Anaesth. and Analg. 52: 495-501 (1973).

10. Dhipps, R.D., Eckenhoff, J.E., \& VAndaM, L.D. Introduction to anaesthesia. The principles of safe practice. 4th edition. Philadelphia, London, Toronto. W.B. Saunders Co. p. 179 (1972).

11. Brgland, B., Goetzee, B., Maclagan, J., \& Zaimis, E. The effect of lowered muscle temperature on the action of neuromuscular blocking drugs. J. Physiol. 141; 425-434 (1958).

12. Feldman, S.A. \& Tyrrell, M.F. A new theory of the termination of action of the muscle relaxants, Proceedings of the Royal Society of Medicine 63: 692-695 (1970). 